\title{
Platelets as messengers of early-stage cancer
}

\author{
Siamack Sabrkhany ${ }^{1} \cdot$ Marijke J. E. Kuijpers $^{2} \cdot$ Mirjam G. A. oude Egbrink $^{1} \cdot$ Arjan W. Griffioen $^{3}$
}

Received: 23 September 2020 / Accepted: 28 January 2021 / Published online: 26 February 2021

(C) The Author(s) 2021

\begin{abstract}
Platelets have an important role in tumor angiogenesis, growth, and metastasis. The reciprocal interaction between cancer and platelets results in changes of several platelet characteristics. It is becoming clear that analysis of these platelet features could offer a new strategy in the search for biomarkers of cancer. Here, we review the human studies in which platelet characteristics (e.g., count, volume, protein, and mRNA content) are investigated in early-stage cancer. The main focus of this paper is to evaluate which platelet features are suitable for the development of a blood test that could detect cancer in its early stages.
\end{abstract}

Keywords Platelets $\cdot$ Biomarker $\cdot$ Early-stage $\cdot$ Cancer

\section{Introduction}

Cancer is one of the foremost causes of death worldwide [1]. Over the past decades, researchers have been focused on the discovery of new approaches for improved therapy of cancer, ultimately aiming for cure. It is known that an earlier detection of cancer will profoundly improve the success of patient treatment and enhance overall survival [2-4]. However, early detection of cancer is notoriously difficult and efficient bloodbased biomarkers are hardly available. Up to now, many blood-based sources of biomarkers, such as plasma, serum and circulating RNA/DNA, tumor cells, or exosomes/microparticles, have been exploited in the search for the ideal biomarker allowing detection of cancer at its earliest stages [5]. Remarkably, platelets have long been neglected in blood biomarker research [6], in spite of the growing evidence that platelets are important in the development and progression of cancer [7-9]. Platelets have been shown to possess an important biological role at several stages of malignant disease, such as angiogenesis [10], cell proliferation [11], cell

Arjan W. Griffioen

a.griffioen@amsterdamumc.nl

1 Department of Physiology, Cardiovascular Research Institute Maastricht, Maastricht University, Maastricht, The Netherlands

2 Department of Biochemistry, Cardiovascular Research Institute Maastricht, Maastricht University, Maastricht, The Netherlands

3 Angiogenesis Laboratory, Cancer Center Amsterdam, Department of Medical Oncology, VU University Medical Center, Amsterdam UMC, Amsterdam, The Netherlands invasiveness, and metastasis $[12,13]$. In addition, there are indications that inhibition of platelet function has an inhibitory effect on tumor growth and that this increases overall survival of patients [14-17].

The interaction between platelets and cancer is evidently reciprocal [18]. Platelets have a stimulatory effect on cancer progression $[7,8]$, while at the same time, the presence of a malignant disease affects multiple platelet characteristics and functions. For example, malignant tumors have been shown to increase platelet numbers and hijack platelet functions in order to fuel cancer progression [19]. Moreover, there are several promising studies showing that platelet features from patients with cancer are already altered in early stages of malignant disease [20-24]. Hence, the use of platelet characteristics is expected to provide an innovative strategy in the search for biomarkers of early-stage cancer [9]. In the current paper, we will briefly review the mechanisms by which platelets stimulate cancer progression and present an overview of literature describing the effect of cancer presence on platelet activation, count, volume, mRNA/protein content, and function, as well as whether these features could be used as biomarkers of early-stage cancer.

\section{Platelets promote angiogenesis, tumor growth, and metastasis}

Cancerous tumors are also viewed as wounds that never heal [25], because they induce local and systemic coagulation and platelet adhesion, activation, aggregation, and secretion 
[26-28]. During the past decades, it has become increasingly clear that tumors can use platelets to stimulate angiogenesis and induce cancer cell proliferation and metastasis (Fig. 1) [7, $10,29]$.

The composition of the tumor vasculature is different from the normal vasculature [30, 31]. Blood vessels in a tumor are characterized as immature and leaky, due to the exposure to the tumor microenvironmental milieu. Hence, the tumor endothelium can be discontinuous, providing prothrombotic conditions via the expression of thrombotic proteins, e.g., tissue factor, collagen, von Willebrand factor, podoplanin, and integrins [32-36]. Eventually, these factors, combined with the low blood flow, create a thrombophilic tumor microenvironment $[25,37]$. This prothrombotic state initiates platelet adhesion and activation, followed by secretion of the rich granule content of platelets within the tumor [10].

Platelet granules contain an enormous amount of bioactive growth factors, e.g., chemokines, cytokines, and matrix metalloproteinases (MMPs). Upon secretion, these molecules can support tumor growth and progression, mainly via, but not limited to, induction of tumor angiogenesis $[10,38]$. This rate-limiting step in cancer growth is intricately regulated by a plethora of growth factors and the involvement of tumor cells and different tumor stroma cells (e.g., endothelial cells, pericytes, smooth muscle cells, fibroblasts, platelets, and a variety of mature and immature immune cells) [39]. The role of platelets in this process is slowly becoming elucidated [7, 10, 40-43]. By secreting their bioactive molecules within the tumor microenvironment, platelets not only play an important role in the regulation of tumor angiogenesis but also in vascular stabilization and integrity [41-45], as well as resistance to therapy $[46,47]$.

It has been described that the secretome and microparticles released from activated platelets increase proliferation of several cancer cell lines (e.g., ovarian and hepatocellular carcinoma cancer cells) $[11,48]$. In addition, platelets are able to increase resistance to mitochondrial apoptosis in cancer cells $[41,42,49]$. At the same time, platelets support tumor cell survival and transport in the circulation once these cells detach from the primary tumor site. To this end, platelets are able to attach to circulating tumor cells via several adhesion receptors, which results in the formation of tumor cell-platelet aggregates [50]. Exploiting this mechanism, circulating tumor cells are able to protect themselves from immune surveillance $[50,51]$. Platelets aggregated to the tumor cell surface also support adhesion to the endothelium of potential metastatic

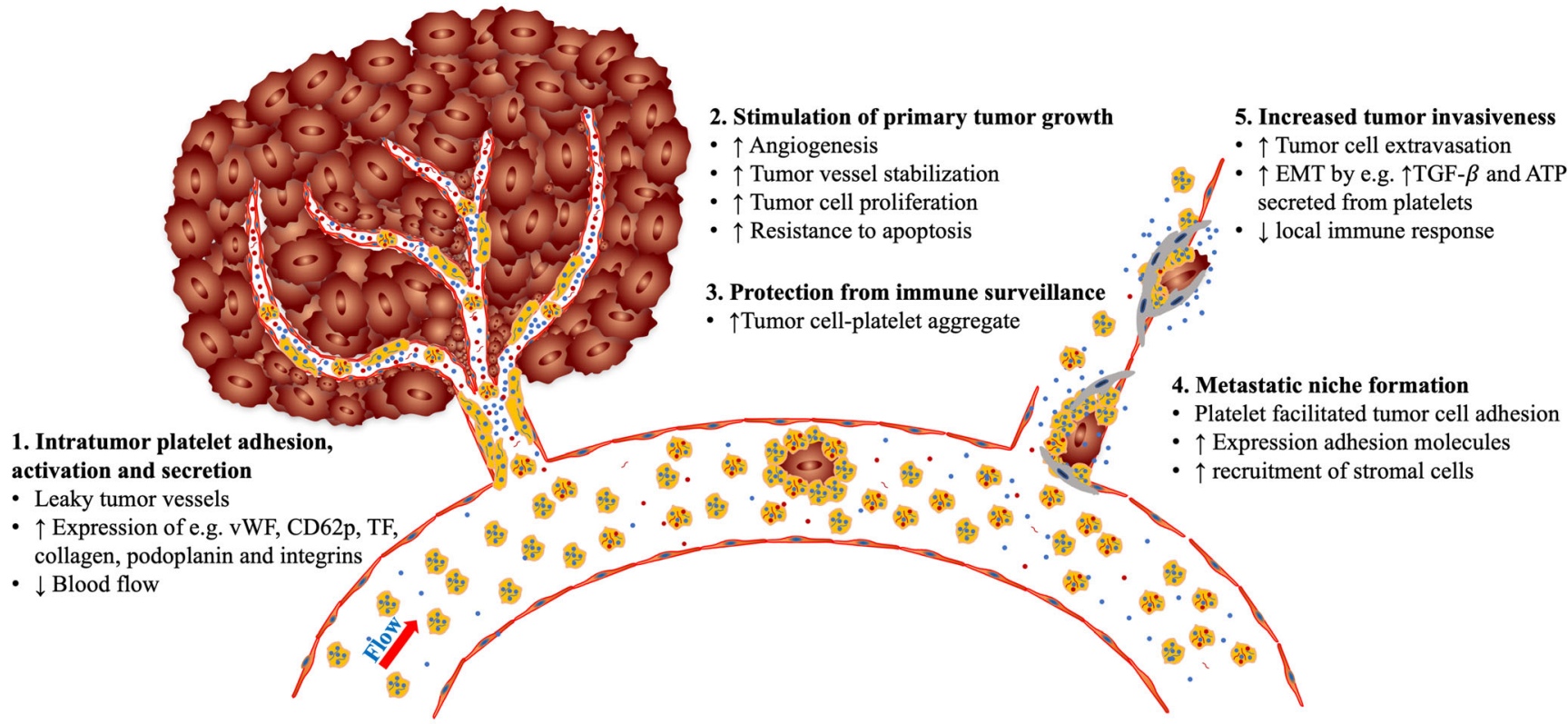

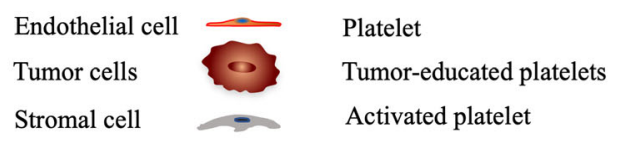

Fig. 1 Platelets promote tumor angiogenesis cancer growth and metastasis. (1) The prothrombotic tumor microenvironment induces platelet adhesion, activation, and secretion in the (angiogenic) blood vessels within the tumor. (2) Platelet secretome and microparticles induce tumor angiogenesis, vessel stabilization, cancer cell proliferation, and resistance to apoptosis. At the same time, platelets sequester proteins and mRNA from the tumor (and become so-called tumor-educated

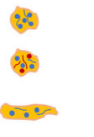

Platelet-derived mRNA
Tumor-derived mRNA
Tumor cell-platelet aggregate platelets). (3) Tumor cell-platelet aggregate formation shields circulating tumor cells from the immune system. (4) Platelets support metastatic niche formation by inducing the expression of adhesion molecules and recruitment of stromal cells at potential metastatic sites. (5) Platelet secretome increases tumor cell invasiveness by inducing epithelialmesenchymal transition (EMT) and inhibiting local immune response 
sites [52]. Platelet-vessel wall interaction induces the expression of multiple adhesion molecules on the luminal side of the vessels which increases recruitment of stromal cells (e.g., monocytes) [51, 53]. In addition, CD97 expressed on tumor cells results in platelet activation and secretion of plateletderived mediators, such as ATP, lysophosphatidic acid, and TGF- $\beta$, that disrupt endothelial junctions and thereby increase tumor cell invasiveness and extravasation into healthy tissue $[12,54]$. Furthermore, TGF- $\beta$ secreted from platelets and direct platelet-tumor cell contact activates the TGF- $\beta /$ Smadand the NF- $\mathrm{KB}$ pathways in malignant cells [12]. This stimulates enhanced tumor cell aggressiveness by epithelialmesenchymal transition (EMT) $[12,13,52]$. Platelets can induce cancer cells to upregulate mesenchymal markers such as SNAIL, vimentin, fibronectin, and MMP-9, and stimulate downregulation of E-cadherin, which is a fundamental step in EMT $[12,55]$. At the same time, TGF- $\beta$ downregulates the local immune response, for example, by inhibiting the expression of NKG2D, the major receptor of several MHC class I homologs, on natural killer cells $[13,56]$.

\section{Platelet inhibition reduces cancer progression}

As tumors use (activated) platelets to boost tumor angiogenesis, tumor growth, and metastasis (Fig. 1), it has been suggested that targeting platelets may result in inhibition of cancer progression. Indeed, reduction of platelet count in tumorbearing mice reduced tumor angiogenesis, tumor growth, and metastasis [41, 42, 57-59]. Besides their stimulatory effect on tumor growth, platelets are critical at stabilizing the tumor vasculature and preventing intratumoral hemorrhage [41, 43]. In addition, multiple in vivo studies have shown that treatment with aspirin or clopidogrel, both inhibitors of platelet aggregation, reduces tumor angiogenesis and tumor growth, as well as cancer progression in tumor-bearing mice [17, 44, 60-63]. Furthermore, large epidemiological studies suggested that daily intake of aspirin at low anti-platelet doses reduces the risk of development of several types of cancer [14, 16]. Also, a prospective cohort study revealed that daily aspirin intake after the diagnosis of colorectal cancer decreased cancer-specific death and overall mortality [64]. Although the exact mechanism underlying this effect of aspirin is still poorly understood, several recent studies suggest that inhibition of platelets by aspirin reduced their ability to induce cancer cell proliferation through modulation of the c-MYC oncoprotein and inhibition of platelet-derived COX-1/thromboxane A2 $[17,26]$. However, the effect of aspirin on tumor growth could also be due to its inhibitory effect on COX-2 expressed on tumor cells $[65,66]$. Large randomized placebo-controlled prospective human studies investigating the effect of platelet inhibition on overall survival of patients with cancer are ongoing, and may provide further clinical evidence of the protective properties of anti-platelet agents against cancer [67].

Over the past few years, there are also an increasing number of studies indicating that certain anticancer therapies, specifically tyrosine kinase inhibitors (TKIs), reduce platelet count, as well as platelet activation [68-70]. This class of drugs is widely used for the clinical management of a variety of cancer types, mostly in combination with more conventional treatment strategies. It is therefore assumed that next to the direct effect of these drugs on tumor cells, they may lend part of their activity indirectly via the inhibition of platelet function.

\section{Tumor cells influence platelet characteristics}

Activated platelets stimulate cancer progression at different stages, making platelets an attractive target in the battle against cancer. At the same time, the presence of a tumor has a major influence on platelet characteristics, possibly through effects at the level of the megakaryocytes. These characteristics include platelet count, volume, protein and mRNA content, and activation state; responses at the level of these features make platelets an interesting new target for blood biomarker research for the detection of early-stage cancer [9].

\subsection{Platelet count}

The association between platelet count and malignant disease is well recognized. In the presence of occult cancer, platelet production can be heavily increased in response to various tumor-derived and systemic factors (Fig. 2) [7, 19]. Platelets are produced in the bone marrow through the formation of proplatelets by terminally differentiated megakaryocytes [36]. In vivo studies have demonstrated that tumor-bearing mice have increased serum levels of megakaryocytestimulating factors, such as IL-6, M-CSF, and SDF-1 $\alpha$ [71]. Also in patients, plasma levels of G-CSF, GM-CSF, and IL-6 were found to be elevated, resulting in enhanced platelet production and paraneoplastic thrombocytosis [72]. Pucci et al. described platelet factor-4 (PF-4) as a cancer-enhancing endocrine signal-stimulating bone marrow megakaryopoiesis, which is associated with a decreased survival of lung cancer patients [73]. However, the chicken-or-the-egg question is still unanswered: either an increase in thrombopoietic factors leads to an increase in platelet count with subsequent stimulation of tumor growth, or an already aggressive tumor secretes thrombopoietic factors, which results in an increase in platelet count. Nonetheless, increased levels of thrombopoietic factors and elevated numbers of platelets are often observed in patients with cancer. 
We and others have demonstrated a clear correlation between platelet count and the presence of cancer [19, 23, 74]. Also, there is accumulating evidence that thrombocytosis (i.e., a platelet count above $400 \times 10^{9}$ platelets $/ \mathrm{L}$ ) is an independent predictor of poor prognosis in various types of cancer [19]. However, the value of platelet count as a biomarker of earlystage cancer is still unclear. A large clinical study with approximately 140,000 patients showed that almost $40 \%$ of patients with idiopathic thrombocytosis (i.e., without inflammatory disease or iron deficiency) exhibit some form of occult malignancy [75]. In addition, a recent systematic review of studies performed in a primary care setting suggests that thrombocytosis is a marker of increased risk of cancer presence in adults older than 40 years [76]. In this study, the incidence of cancer in the year following the assessment of thrombocytosis was $11.6 \%$ in males and $6.2 \%$ in females, as compared to 4.2 and $2.2 \%$ in males and females with a normal platelet count, respectively. Interestingly, in this study, thrombocytosis was the strongest predictor of lung and colorectal cancer. While the studies above suggest that thrombocytosis could be a risk factor of undiagnosed cancer in primary care setting, it is not specified whether these cancer diagnoses concerned early- or late-stage cancer. Overall, platelet count may be a good predictor of poor prognosis in patients with cancer; however, platelet count as a single measurement is probably not sufficient for detection of early-stage cancer.

\subsection{Platelet volume}

Platelet volume is established during platelet formation, where preplatelets are transformed to proplatelets [77]. Platelet volume (normal range: 9.4-12.3 fL) is genetically determined and is fairly stable over the lifetime of healthy individuals [78], but it can vary during a wide range of diseases. Changes in mean platelet volume (MPV) have been demonstrated in cardiovascular disease, cerebrovascular disease, peripheral artery disease, Crohn's disease, and colitis [79-83]. In addition, from studies by us and others, it is becoming increasingly clear that MPV is also affected during malignant diseases [23, 84-87]. Electron microscopy has revealed that platelets of patients with ovarian tumors have more mitochondria and significantly smaller microtubules compared to platelets from healthy individuals [88]. We demonstrated that MPV is elevated in patients with lung or head of pancreas cancer [23]. Furthermore, a recent meta-analysis confirmed that the MPV of treatment-naïve patients with malignant tumors was significantly higher compared to the MPV of healthy individuals, which generally seemed to normalize after treatment [84].

Over the past years, accumulating evidence suggests that the platelet population within one individual is heterogenous in platelet structure and activation properties [78, 89]. This heterogeneity is most likely the result of differences during thrombopoiesis (e.g., by dissimilar megakaryocyte proplatelet formation), imbalanced platelet priming, environmental conditions and platelet ageing [90]. Therefore, changes in MPV could be a reflection of proinflammatory and/or prothrombotic conditions where thrombopoiesis is affected by inflammatory cells and bioactive molecules such as IL-6 and C-reactive protein [91]. It is suggested that the largest platelets in an individual are associated with increased platelet aggregation, betathromboglobulin secretion, thromboxane synthesis, and metabolic and enzymatic activity $[92,93]$. Consequently, larger platelets can be assumed to be more reactive, as compared to smaller platelets as suggested in patients with coronary artery disease [92]. This increased reactivity is, among others, due to an increase in copy numbers of integrin $\alpha \operatorname{IIb} \beta 3$ and glycoprotein (GP) Ib $\alpha$ on larger platelets $[94,95]$. This is in agreement with other studies, where an increase in platelet activation is demonstrated in patients with cancer $[23,69,96]$. In addition, several retrospective and prospective studies suggest that larger platelets are more reactive and that patients with large platelets are at higher risk for thrombotic events [97-99]. It is important to realize, however, that platelet volume is not the only factor determining platelet reactivity to stimuli $[78,90]$.

Thus far, the impact of MPV in patients with malignant tumors is not fully understood.

There are several studies, which reveal that high MPV is a predictor of poor prognosis in various types of cancer [85, 100-102]. However, the role of MPV as an early messenger of cancer presence seems to be limited, as it is mostly affected in later stages of the disease [86, 87, 100, 103]. In addition, while in most studies the differences in MPV between patients with advanced cancer and controls are significant, the changes in platelet volume between patients and controls are very small. For example, MPV has been shown to be significantly higher in patients with gastric or endometrium cancer compared to healthy controls $[86,104]$. However, MPV was 8.31 fL (range 7.53-9.09) or 7.8 fL (range 6.2-11.3) in patients with gastric or endometrium cancer, respectively, whereas in healthy controls, MPV was $7.85 \mathrm{fL}$ (range 7.4-8.3) and 7.2 fL (range 1.6-14.9), respectively. These small differences can be easily masked by a wide range of variables that can impact MPV. Therefore, MPV as a single measurement does not seem to be a good marker to distinguish patients with earlystage cancer from healthy individuals.

\subsection{Platelet protein content}

Platelets transport a vast amount of bioactive proteins in their granules, including growth factors, chemokines, and proteases, which they can secrete upon activation [10]. In vivo studies with mice bearing human tumors have demonstrated that platelets are able to sequester proteins that are secreted from tumors [71]. This resulted in higher concentrations of tumor-derived factors (such as TGF- $\beta$, MCP-1, RANK, and TIMP-1) inside platelets due to the 
presence of cancer [71]. In addition, platelets of tumor-bearing mice were observed to contain increased levels of thrombospondin-1 (TSP-1), which is highly correlated to tumor progression. After resection of the tumor, these levels decreased to baseline [105]. Upregulation of proteins, such as TSP-1 and platelet factor 4 (PF4), inside platelets could even be used to detect clinically undetectable tumors $\left(<1 \mathrm{~mm}^{3}\right)$ in mice $[105,106]$.

Multiple studies in humans have also demonstrated changes in platelet protein content in patients with cancer (Table 1). However, part of these results are derived from indirect measurements where the platelet content was not measured but calculated (Platelet content $=\frac{\text { Serum concentration-plasma concentration }}{\text { Platelet count in whole blood }}$ ) from serum and plasma concentrations. Nevertheless, there are also studies where bioactive factors were directly measured in isolated platelets from patients with cancer and compared to platelets of healthy individuals [20, 23, 107]. Peterson et al. demonstrated elevated concentrations of VEGF, PF4, and PDGF in platelets of patients with colorectal cancer [20]. In addition, they showed that these changes in platelets provided a statistically significant discrimination between patients and age-matched healthy controls [20]. While approximately half of the patients included in this study had early-stage (I-II) colorectal cancer, the small sample size prevented detection of a correlation between cancer stage and platelet content. In our study of 2017 [23], we demonstrated a significant increase in concentrations of VEGF and PDGF in platelets of patients with early-stage (I-II) lung cancer compared to platelets of a healthy sex- and age-matched control group. In platelets of patients with late-stage (III-IV) lung cancer, we observed a decrease in PF4, CTAPIII, and TSP-1 as compared to the control group, which was similar to a previous study performed in patients with advanced cancer [107]. In patients with head of pancreas cancer only, VEGF was elevated in platelets as compared to controls [23]. Thus, changes in platelet protein content are consistently observed in patients with cancer. Interestingly, the platelet changes appear to be tumor-type-dependent as demonstrated by multiple other studies (Table 1). The combination of changes in multiple platelet characteristics allowed cancer typespecific discrimination between early-stage cancer patients and healthy controls. For this purpose, we used the data from our study to develop a multivariable diagnostic model for both lung and head of pancreas cancer, including platelet count, volume, protein content, and activation status [23]. This model appeared to be able to distinguish patients with early-stage lung or head of pancreas cancer from healthy sex- and age-matched controls [23]. Overall, the above studies suggest that a combination of platelet measurements could be used to distinguish patients with early- or late-stage cancer from healthy individuals.

The changes in platelet content are not limited to the abovementioned proteins. Several years ago, Klement and colleagues demonstrated a substantial change in the platelet proteome of tumor-bearing mice [108]. In 2018, we have performed
Table 1 Expression of proteins in platelets of patients with different cancer types compared to control

\begin{tabular}{|c|c|c|c|}
\hline Protein & $\begin{array}{l}\text { Early-stage } \\
\text { (I-II) }\end{array}$ & $\begin{array}{l}\text { Advanced-stage } \\
\text { (III-IV) }\end{array}$ & $\begin{array}{l}\text { Stage not specified } \\
\text { (I-IV) }\end{array}$ \\
\hline Ang-1 & & & $\mathrm{PC} \sim[117], \mathrm{BC} \uparrow[117]$ \\
\hline bFGF & & & $\mathrm{HCC} \uparrow[118], \mathrm{CRC} \sim[20]$ \\
\hline Clusterin & $\mathrm{CRC} \downarrow[119]$ & $\mathrm{CRC} \downarrow[119]$ & \\
\hline Cofilin-1 & $\mathrm{CRC} \uparrow[119]$ & $\mathrm{CRC} \uparrow[119]$ & \\
\hline CTAPIII & $\begin{array}{l}\mathrm{LC} \sim[23] \\
\mathrm{Ho}- \\
\mathrm{P} \sim[23]\end{array}$ & $\begin{array}{l}\mathrm{LC} \downarrow[23], \\
\quad \mathrm{HoP} \sim[23]\end{array}$ & \\
\hline CXCL12 & & $\mathrm{VC} \downarrow[107]$ & \\
\hline Endostatin & & & $\begin{array}{l}\mathrm{HCC} \uparrow[118], \mathrm{CRC} \sim[20], \\
\quad \mathrm{GBM} \sim[120]\end{array}$ \\
\hline GSH-s & $\mathrm{CRC} \uparrow[119]$ & & \\
\hline HGF & & & $\mathrm{HCC} \uparrow[118]$ \\
\hline PDGF & $\begin{array}{c}\mathrm{LC} \uparrow[23], \\
\mathrm{HoP} \sim \\
{[23]}\end{array}$ & $\begin{array}{l}\mathrm{LC} \sim[23], \\
\quad \mathrm{HoP} \sim[23]\end{array}$ & $\begin{array}{l}\mathrm{CRC} \uparrow[20,121], \mathrm{BC} \uparrow[122] \\
\quad \mathrm{HCC} \sim[118]\end{array}$ \\
\hline PF4 & $\begin{array}{l}\mathrm{LC} \sim[23], \\
\quad \mathrm{Ho}- \\
\mathrm{P} \sim[23]\end{array}$ & $\begin{array}{l}\mathrm{BC} \uparrow[123], \mathrm{LC} \downarrow \\
{[23], \mathrm{VC} \downarrow} \\
{[107]} \\
\mathrm{HoP} \sim[23]\end{array}$ & $\begin{array}{l}\mathrm{CRC} \uparrow[20], \mathrm{BC} \uparrow[122], \\
\mathrm{HCC} \sim[118]\end{array}$ \\
\hline TGF- $\beta$ & & & $\mathrm{BC} \uparrow[122], \mathrm{BC} \sim[124]$ \\
\hline TSP-1 & $\begin{array}{l}\mathrm{LC} \sim[23] \\
\mathrm{Ho-} \\
\mathrm{P} \sim[23]\end{array}$ & $\begin{array}{l}\mathrm{LC} \downarrow[23], \mathrm{VC} \downarrow \\
\quad[107], \mathrm{HoP} \sim \\
{[23]}\end{array}$ & $\begin{array}{l}\mathrm{BC} \sim[122,124], \mathrm{CRC} \sim[20] \\
\mathrm{HCC} \sim[118]\end{array}$ \\
\hline VEGF & $\begin{array}{c}\mathrm{LC} \uparrow[23], \\
\mathrm{HoP} \uparrow \\
{[23],} \\
\mathrm{BC} \uparrow \\
{[125]}\end{array}$ & $\begin{array}{l}\mathrm{LC} \uparrow[23,126], \\
\mathrm{HoP} \uparrow[23], \\
\mathrm{BC} \uparrow[123, \\
125]\end{array}$ & $\begin{array}{c}\mathrm{CRC} \uparrow[20,121], \mathrm{GBM} \uparrow \\
{[120], \mathrm{HCC} \uparrow[118], \mathrm{PC} \uparrow} \\
{[117], \mathrm{BC} \uparrow[122,124,} \\
127]\end{array}$ \\
\hline
\end{tabular}

Expression (increased $(\uparrow)$, decreased $(\downarrow)$, not changed $(\sim)$ ) of proteins in platelets of patients with lung (LC), colorectal (CRC), breast (BC), glioblastoma (GBM), head of pancreas (HoP), hepatocellular (HCC), prostate (PC) cancer or mix of various cancers (VC) compared to a (healthy) control group. Empty spaces indicate a lack of suitable research

Ang-1 angiopoietin-1, $b F G F$ basic fibroblast growth factor, CTAPIII connective tissue activating peptide-III, $G S H-S$ glutathione synthetase, $H G F$ hepatocyte growth factor, $P D G F$ platelet-derived growth factor, $P F 4$ platelet factor-4, TGF- $\beta$ transforming growth factor beta, TSP-1 trombospondin-1, $V E G F$ vascular endothelial growth factor

the first study in humans, in which 139 differentially expressed proteins were found in platelets of patients with early-stage lung or head of pancreas cancer as compared to healthy individuals of comparable age and gender [22]. Furthermore, surgical removal of the malignant tumor resulted in normalization of the platelet proteome [22]. Interestingly, we found that molecular content changes in head of pancreas cancer were more pronounced and showed a different profile as compared to the lung cancer platelet proteome, which supports the notion of tumortype dependency of platelet changes (Fig. 2). Multiple potential platelet-derived biomarkers of early-stage cancer were identified by the comparison of the platelet proteome in cancer patients with that of sex- and age-matched healthy controls [22]. 
a

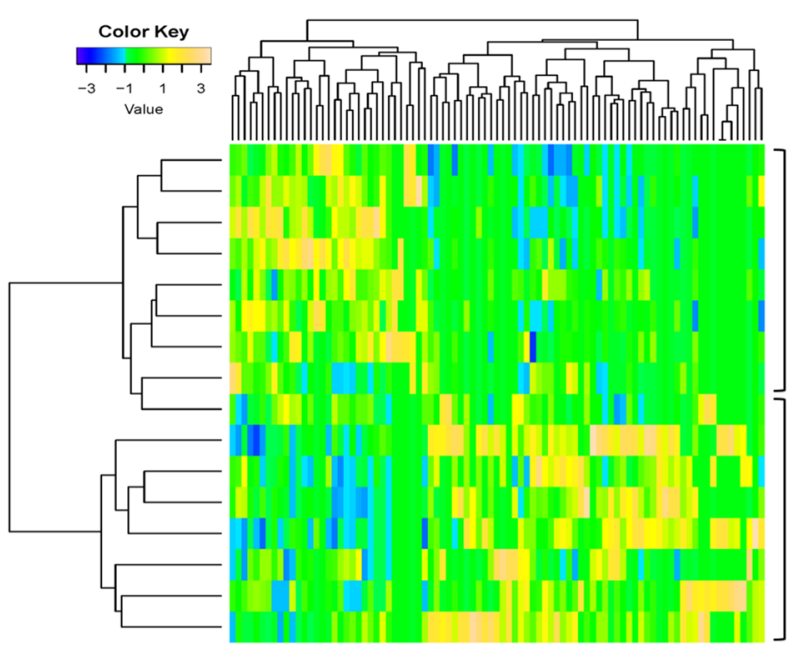

Fig. 2 Heat map and supervised cluster analysis of protein expression data from platelets of early-stage lung or head of pancreas cancer (HoP cancer) patients compared to healthy sex- and age-matched controls. Cancer type-specific supervised cluster analysis clearly separates the

Several mechanisms underlie the changes in platelet proteome of patients with malignant disease (Fig. 1). Proteins present in platelets are either synthesized by megakaryocytes that produce the platelets, or are absorbed by megakaryocytes and/ or platelets themselves from the blood [105, 108, 109]. The concept of tumor-educated platelets (TEPs) assumes that platelets can directly take up bioactive factors from tumor cells, while residing temporarily in the tumor [21, 22]. As a consequence, the platelet proteome mirrors the tumor-based changes and the concentration of potential tumor reporter proteins can be considerably higher inside platelets than in plasma. This enables more accurate measurement, as compared to quantification in plasma, making platelets an attractive source of biomarker discovery [20, 23, 108]. Several studies even suggest that in the presence of a growing tumor, changes inside platelets precede alterations in plasma $[20,105,106$, 108]. This implies that measurements of potential biomarkers inside platelets could be more sensitive for detection of earlystage cancer than plasma measurements.

\subsection{Platelet mRNA content}

The platelet mRNA profile is currently emerging as a new potential source in cancer biomarker research $[21,24,110]$. Platelets do not contain a nucleus and, therefore, the mRNA transcripts either originate from megakaryocytes during platelet synthesis $[36,111]$ or are absorbed from the blood during circulation and/or interaction with tumor or other cell types [112]. Several mechanisms have been described that determine the platelet mRNA profile. Nilsson et al. demonstrated tumor-derived mRNA transfer (mutant EGFRvIII) from cancer cells to blood platelets of healthy individuals in vitro [110]. b Head of pancreas cancer

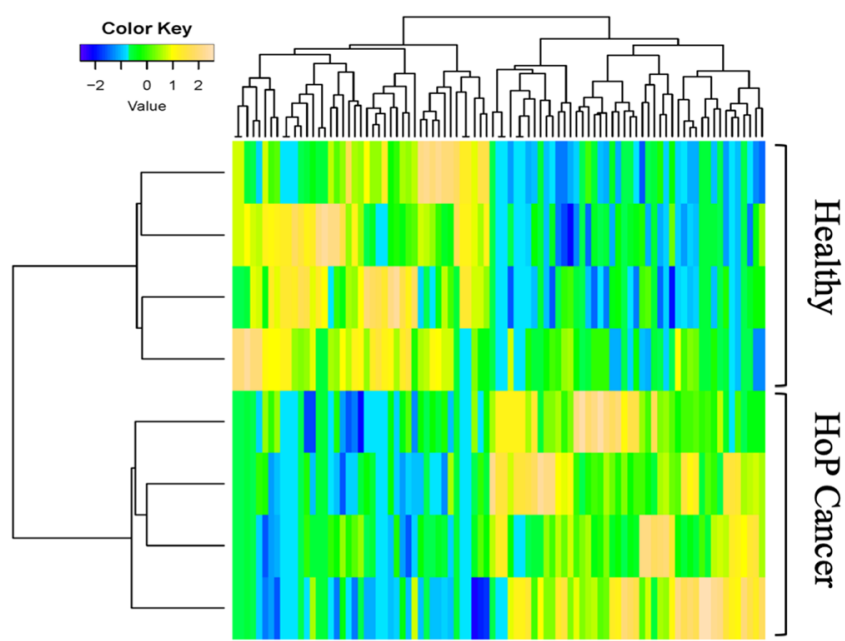

platelet proteome of patients with early-stage lung cancer (a) or head of pancreas cancer (b) from healthy controls. Reprinted from [10] with permission

In addition, they showed that platelets isolated from glioma or prostate cancer patients also contained the cancer-associated mRNA biomarkers EGFRvIII and PCA3. Most likely, platelets take up these mRNAs via microvesicle-dependent endocytosis [113], but a microvesicle-independent mechanism is also possible [114]. In addition, induction of platelet activation by external stimuli (e.g., collagen or bioactive molecules secreted by a tumor) stimulates maturation of resident premRNAs in platelets and results in RNA splicing in platelets during activation [115].

The potential of using platelet mRNA as a diagnostic tool in patients with cancer was emphasized by a study of Best et al., who discovered changes in platelet mRNA profiles in cancer patients [21]. In this study, the platelet mRNA profile of patients with several types of cancer was compared to the platelet mRNA profile of healthy individuals. This study demonstrated that the platelet mRNA profile was affected in almost all cancer patients. A combination of changed mRNAs allowed good discrimination between cancer patients and healthy individuals with high sensitivity (96\%) and specificity $(92 \%)$. An important limitation of this study was the nature of the control group that was clearly younger and had a different gender distribution than most of the cancer groups. This is especially important as we and others have shown that changes in platelet characteristics are correlated with age and sex $[23,116]$. In a follow-up study, Best et al. used a particle swarm optimization-enhanced algorithm to select an mRNA biomarker panel that could distinguish patients with NSCLC (non-small cell lung cancer) from healthy individuals [24]. A panel of 1000 genes resulted in accurate detection of earlyand late-stage NSCLC when compared to an unmatched control group. Matched evaluation for age and smoking status 
(panel of 830 genes) also resulted in a statistically significant discrimination of patients with NSCLC from healthy controls. Unfortunately, the latter analysis was not subdivided in earlyand late-stage cancer. Overall, platelet-derived mRNA seems to be a sensitive and promising new tool in the search for biomarkers of early-stage cancer. Further studies are still needed to validate these encouraging results.

\section{Conclusion}

Early detection of cancer allows a significant improvement of overall survival of patients. During the past years, platelet characteristics are emerging as a promising source for biomarkers of cancer. This review summarizes and discusses studies in which platelet features (e.g., count, volume, protein, and mRNA profile) are explored in early-stage as well as latestage cancer. Platelet count and volume appear to have a more prognostic value and their importance as biomarkers of earlystage cancer remains to be demonstrated. However, a combination of platelet count, volume, and selected platelet-derived proteins could be used to discriminate patients with earlystage cancer from healthy individuals. Most promising data are from patient studies illustrating vast changes in platelet proteome and mRNA content. These changes occur already in early stages of cancer and illustrate that the platelet content could be a rich source of potential biomarkers. In addition, these profiles could be exploited to provide information on the organ of origin, which could provide a lead for clinical follow-up diagnostics to confirm the tumor location.

Future large-scale studies are needed in general population or in people who have a genetic disposition to acquire certain types of cancer (e.g., patients with mutation in BRCA1/2 or Lynch syndrome). These individuals have a very high lifetime risk of developing cancer and are therefore frequently screened with invasive and/or imaging techniques to detect potential tumors. These patients are therefore an exceptional group to study, to investigate whether platelet changes precede clinically detectable tumors.

Authors' contributions All authors contributed equally.

Funding This work was supported by the KWF Cancer Society VUMC2018-11651 (to AWG) and Kootstra Talent Fellowship CD.18.0008 (to SS).

\section{Declarations}

Conflict of interest The authors declare no conflict of interest.

Ethical approval No ethical approvals are required for this review.

Informed consent Informed consent is not required for this review.
Open Access This article is licensed under a Creative Commons Attribution 4.0 International License, which permits use, sharing, adaptation, distribution and reproduction in any medium or format, as long as you give appropriate credit to the original author(s) and the source, provide a link to the Creative Commons licence, and indicate if changes were made. The images or other third party material in this article are included in the article's Creative Commons licence, unless indicated otherwise in a credit line to the material. If material is not included in the article's Creative Commons licence and your intended use is not permitted by statutory regulation or exceeds the permitted use, you will need to obtain permission directly from the copyright holder. To view a copy of this licence, visit http://creativecommons.org/licenses/by/4.0/.

\section{References}

1. Siegel, R. L., Miller, K. D., \& Jemal, A. (2018). Cancer statistics, 2018. CA: a Cancer Journal for Clinicians, 68(1), 7-30.

2. Etzioni, R., Urban, N., Ramsey, S., McIntosh, M., Schwartz, S., Reid, B., Radich, J., Anderson, G., \& Hartwell, L. (2003). The case for early detection. Nature reviews. Cancer, 3(4), 243-252.

3. Wolf, A. M., Wender, R. C., Etzioni, R. B., Thompson, I. M., D'Amico, A. V., Volk, R. J., Brooks, D. D., Dash, C., Guessous, I., Andrews, K., DeSantis, C., Smith, R. A., \& American Cancer Society Prostate Cancer Advisory Committee. (2010). American Cancer Society guideline for the early detection of prostate cancer: update 2010. CA: a Cancer Journal for Clinicians, 60(2), 70-98.

4. Hiom, S. C. (2015). Diagnosing cancer earlier: reviewing the evidence for improving cancer survival. British Journal of Cancer, 112(Suppl 1), S1-S5.

5. Uttley, L., Whiteman, B. L., Woods, H. B., Harnan, S., Philips, S. T., \& Cree, I. A. (2016). Building the evidence base of bloodbased biomarkers for early detection of cancer: a rapid systematic mapping review. EBioMedicine, 10, 164-173.

6. Sabrkhany, S., Kuijpers, M. J., Verheul, H. M., Griffioen, A. W., \& oude Egbrink, M. G. (2015). Platelets: an unexploited data source in biomarker research. The Lancet. Haematology, 2(12), e512-e513.

7. Haemmerle, M., Stone, R. L., Menter, D. G., Afshar-Kharghan, V., \& Sood, A. K. (2018). The platelet lifeline to cancer: challenges and opportunities. Cancer Cell, 33(6), 965-983.

8. Plantureux, L., Crescence, L., Dignat-George, F., Panicot-Dubois, L., \& Dubois, C. (2018). Effects of platelets on cancer progression. Thrombosis Research, 164(Suppl 1), S40-S47.

9. Sabrkhany, S., Kuijpers, M. J. E., Griffioen, A. W., \& Oude Egbrink, M. G. A. (2018). Platelets: the holy grail in cancer blood biomarker research? Angiogenesis, 22, 1-2.

10. Sabrkhany, S., Griffioen, A. W., \& Oude Egbrink, M. G. (2011). The role of blood platelets in tumor angiogenesis. Biochimica et Biophysica Acta, 1815(2), 189-196.

11. Cho, M. S., Bottsford-Miller, J., Vasquez, H. G., Stone, R., Zand, B., Kroll, M. H., Sood, A. K., \& Afshar-Kharghan, V. (2012). Platelets increase the proliferation of ovarian cancer cells. Blood, 120(24), 4869-4872.

12. Labelle, M., Begum, S., \& Hynes, R. O. (2011). Direct signaling between platelets and cancer cells induces an epithelialmesenchymal-like transition and promotes metastasis. Cancer Cell, 20(5), 576-590.

13. Labelle, M., Begum, S., \& Hynes, R. O. (2014). Platelets guide the formation of early metastatic niches. Proceedings of the National Academy of Sciences of the United States of America, 111(30), E3053-E3061. 
14. Rothwell, P. M., Wilson, M., Price, J. F., Belch, J. F., Meade, T. W., \& Mehta, Z. (2012). Effect of daily aspirin on risk of cancer metastasis: a study of incident cancers during randomised controlled trials. Lancet, 379(9826), 1591-1601.

15. Algra, A. M., \& Rothwell, P. M. (2012). Effects of regular aspirin on long-term cancer incidence and metastasis: a systematic comparison of evidence from observational studies versus randomised trials. The Lancet Oncology, 13(5), 518-527.

16. Burn, J., Gerdes, A. M., Macrae, F., Mecklin, J. P., Moeslein, G., Olschwang, S., Eccles, D., Evans, D. G., Maher, E. R., Bertario, L., Bisgaard, M. L., Dunlop, M. G., Ho, J. W., Hodgson, S. V., Lindblom, A., Lubinski, J., Morrison, P. J., Murday, V., Ramesar, R., Side, L., Scott, R. J., Thomas, H. J., Vasen, H. F., Barker, G., Crawford, G., Elliott, F., Movahedi, M., Pylvanainen, K., Wijnen, J. T., Fodde, R., Lynch, H. T., Mathers, J. C., Bishop, D. T., \& CAPP2 Investigators. (2011). Long-term effect of aspirin on cancer risk in carriers of hereditary colorectal cancer: an analysis from the CAPP2 randomised controlled trial. Lancet, 378(9809), 20812087.

17. Lucotti, S., Cerutti, C., Soyer, M., Gil-Bernabe, A. M., Gomes, A. L., Allen, P. D., et al. (2019). Aspirin blocks formation of metastatic intravascular niches by inhibiting platelet-derived COX-1/ thromboxane A2. The Journal of Clinical Investigation, 129(5), $1845-1862$.

18. Goubran, H. A., Burnouf, T., Radosevic, M., \& El-Ekiaby, M. (2013). The platelet-cancer loop. European Journal of Internal Medicine, 24(5), 393-400.

19. Lin, R. J., Afshar-Kharghan, V., \& Schafer, A. I. (2014). Paraneoplastic thrombocytosis: the secrets of tumor self-promotion. Blood, 124(2), 184-187.

20. Peterson, J. E., Zurakowski, D., Italiano Jr., J. E., Michel, L. V., Connors, S., Oenick, M., D’Amato, R. J., Klement, G. L., \& Folkman, J. (2012). VEGF, PF4 and PDGF are elevated in platelets of colorectal cancer patients. Angiogenesis, 15(2), 265-273.

21. Best, M. G., Sol, N., Kooi, I., Tannous, J., Westerman, B. A., Rustenburg, F., Schellen, P., Verschueren, H., Post, E., Koster, J., Ylstra, B., Ameziane, N., Dorsman, J., Smit, E. F., Verheul, H. M., Noske, D. P., Reijneveld, J. C., Nilsson, R. J. A., Tannous, B. A., Wesseling, P., \& Wurdinger, T. (2015). RNA-Seq of tumoreducated platelets enables blood-based pan-cancer, multiclass, and molecular pathway cancer diagnostics. Cancer Cell, 28(5), 666676.

22. Sabrkhany, S., Kuijpers, M. J. E., Knol, J. C., Olde Damink, S. W. M., Dingemans, A. C., Verheul, H. M., et al. (2018). Exploration of the platelet proteome in patients with early-stage cancer. Journal of Proteomics, 177, 65-74.

23. Sabrkhany, S., Kuijpers, M. J. E., van Kuijk, S. M. J., Sanders, L., Pineda, S., Olde Damink, S. W. M., Dingemans, A. M. C., Griffioen, A. W., \& oude Egbrink, M. G. A. (2017). A combination of platelet features allows detection of early-stage cancer. European Journal of Cancer, 80, 5-13.

24. Best, M. G., Sol, N., \& In 't Veld, S. G. J. G., Vancura, A., Muller, M., Niemeijer, A. N., et al. (2017). Swarm intelligence-enhanced detection of non-small-cell lung cancer using tumor-educated platelets. Cancer Cell, 32(2), 238-252.

25. Dvorak, H. F. (1986). Tumors: wounds that do not heal. Similarities between tumor stroma generation and wound healing. The New England Journal of Medicine, 315(26), 1650-1659.

26. Mitrugno, A., Sylman, J. L., Ngo, A. T., Pang, J., Sears, R. C., Williams, C., et al. (2016). Aspirin therapy reduces the ability of platelets to promote colon and pancreatic cancer cell proliferation: implications for the oncoprotein c-MYC. American Journal of Physiology. Cell Physiology, 312, C176-C189.

27. Sierko, E., \& Wojtukiewicz, M. Z. (2007). Inhibition of platelet function: does it offer a chance of better cancer progression control? Seminars in Thrombosis and Hemostasis, 33(7), 712-721.
28. Falanga, A., Russo, L., \& Verzeroli, C. (2013). Mechanisms of thrombosis in cancer. Thrombosis Research, 131(Suppl 1), S59S62.

29. Leblanc, R., \& Peyruchaud, O. (2016). Metastasis: new functional implications of platelets and megakaryocytes. Blood, 128(1), 24 31.

30. Griffioen, A. W., \& Molema, G. (2000). Angiogenesis: potentials for pharmacologic intervention in the treatment of cancer, cardiovascular diseases, and chronic inflammation. Pharmacological Reviews, 52(2), 237-268.

31. Hillen, F., \& Griffioen, A. W. (2007). Tumour vascularization: sprouting angiogenesis and beyond. Cancer Metastasis Reviews, 26(3-4), 489-502.

32. Kasthuri, R. S., Taubman, M. B., \& Mackman, N. (2009). Role of tissue factor in cancer. Journal of Clinical Oncology, 27(29), $4834-4838$.

33. Egan, K., Crowley, D., Smyth, P., O'Toole, S., Spillane, C., Martin, C., Gallagher, M., Canney, A., Norris, L., Conlon, N., McEvoy, L., Ffrench, B., Stordal, B., Keegan, H., Finn, S., McEneaney, V., Laios, A., Ducrée, J., Dunne, E., Smith, L., Berndt, M., Sheils, O., Kenny, D., \& O'Leary, J. (2011). Platelet adhesion and degranulation induce pro-survival and proangiogenic signalling in ovarian cancer cells. PLoS ONE, 6(10), e26125.

34. Hisada, Y., \& Mackman, N. (2017). Cancer-associated pathways and biomarkers of venous thrombosis. Blood, 130(13), 14991506.

35. Fang, M., Yuan, J., Peng, C., \& Li, Y. (2014). Collagen as a double-edged sword in tumor progression. Tumour Biology, 35(4), 2871-2882.

36. Versteeg, H. H., Heemskerk, J. W., Levi, M., \& Reitsma, P. H. (2013). New fundamentals in hemostasis. Physiological Reviews, 93(1), 327-358.

37. Nagy, J. A., Chang, S. H., Dvorak, A. M., \& Dvorak, H. F. (2009). Why are tumour blood vessels abnormal and why is it important to know? British Journal of Cancer, 100(6), 865-869.

38. Wojtukiewicz, M. Z., Sierko, E., Hempel, D., Tucker, S. C., \& Honn, K. V. (2017). Platelets and cancer angiogenesis nexus. Cancer Metastasis Reviews, 36(2), 249-262.

39. Ramjiawan, R. R., Griffioen, A. W., \& Duda, D. G. (2017). Antiangiogenesis for cancer revisited: is there a role for combinations with immunotherapy? Angiogenesis, 20(2), 185-204.

40. Carmeliet, P., \& Jain, R. K. (2011). Principles and mechanisms of vessel normalization for cancer and other angiogenic diseases. Nature reviews. Drug Discovery, 10(6), 417-427.

41. Kisucka, J., Butterfield, C. E., Duda, D. G., Eichenberger, S. C., Saffaripour, S., Ware, J., Ruggeri, Z. M., Jain, R. K., Folkman, J., \& Wagner, D. D. (2006). Platelets and platelet adhesion support angiogenesis while preventing excessive hemorrhage. Proceedings of the National Academy of Sciences of the United States of America, 103(4), 855-860.

42. Ho-Tin-Noe, B., Goerge, T., Cifuni, S. M., Duerschmied, D., \& Wagner, D. D. (2008). Platelet granule secretion continuously prevents intratumor hemorrhage. Cancer Research, 68(16), 6851-6858.

43. Volz, J., Mammadova-Bach, E., Gil-Pulido, J., Nandigama, R., Remer, K., Sorokin, L., Zernecke, A., Abrams, S. I., Ergün, S., Henke, E., \& Nieswandt, B. (2019). Inhibition of platelet GPVI induces intratumor hemorrhage and increases efficacy of chemotherapy in mice. Blood, 133(25), 2696-2706.

44. Battinelli, E. M., Markens, B. A., \& Italiano Jr., J. E. (2011). Release of angiogenesis regulatory proteins from platelet alpha granules: modulation of physiologic and pathologic angiogenesis. Blood, 118(5), 1359-1369. 
45. Yan, M., \& Jurasz, P. (2016). The role of platelets in the tumor microenvironment: from solid tumors to leukemia. Biochimica et Biophysica Acta, 1863(3), 392-400.

46. Huijbers, E. J., van Beijnum, J. R., Thijssen, V. L., Sabrkhany, S., Nowak-Sliwinska, P., \& Griffioen, A. W. (2016). Role of the tumor stroma in resistance to anti-angiogenic therapy. Drug Resistance Updates, 25, 26-37.

47. van Beijnum, J. R., Nowak-Sliwinska, P., Huijbers, E. J., Thijssen, V. L., \& Griffioen, A. W. (2015). The great escape; the hallmarks of resistance to antiangiogenic therapy. Pharmacological Reviews, 67(2), 441-461.

48. He, A. D., Xie, W., Song, W., Ma, Y. Y., Liu, G., Liang, M. L., da, X. W., Yao, G. Q., Zhang, B. X., Gao, C. J., Xiang, J. Z., \& Ming, Z. Y. (2017). Platelet releasates promote the proliferation of hepatocellular carcinoma cells by suppressing the expression of KLF6. Scientific Reports, 7(1), 3989.

49. Velez, J., Enciso, L. J., Suarez, M., Fiegl, M., Grismaldo, A., Lopez, C., et al. (2014). Platelets promote mitochondrial uncoupling and resistance to apoptosis in leukemia cells: a novel paradigm for the bone marrow microenvironment. Cancer Microenvironment, 7(1-2), 79-90.

50. Amo, L., Tamayo-Orbegozo, E., Maruri, N., Eguizabal, C., Zenarruzabeitia, O., Rinon, M., et al. (2014). Involvement of platelet-tumor cell interaction in immune evasion. Potential role of podocalyxin-like protein 1. Front. Oncol, 4, 245.

51. Labelle, M., \& Hynes, R. O. (2012). The initial hours of metastasis: the importance of cooperative host-tumor cell interactions during hematogenous dissemination. Cancer Discovery, 2(12), 1091-1099.

52. Gay, L. J., \& Felding-Habermann, B. (2011). Contribution of platelets to tumour metastasis. Nature reviews. Cancer, 11(2), 123-134.

53. Franco, A. T., Corken, A., \& Ware, J. (2015). Platelets at the interface of thrombosis, inflammation, and cancer. Blood, 126(5), 582-588

54. Ward, Y., Lake, R., Faraji, F., Sperger, J., Martin, P., Gilliard, C., Ku, K. P., Rodems, T., Niles, D., Tillman, H., Yin, J. J., Hunter, K., Sowalsky, A. G., Lang, J., \& Kelly, K. (2018). Platelets promote metastasis via binding tumor CD97 leading to bidirectional signaling that coordinates transendothelial migration. Cell Reports, 23(3), 808-822.

55. Kalluri, R. (2009). EMT: when epithelial cells decide to become mesenchymal-like cells. The Journal of Clinical Investigation, 119(6), 1417-1419.

56. Crane, C. A., Han, S. J., Barry, J. J., Ahn, B. J., Lanier, L. L., \& Parsa, A. T. (2010). TGF-beta downregulates the activating receptor NKG2D on NK cells and CD8+ T cells in glioma patients. Neuro-Oncology, 12(1), 7-13.

57. Stone, R. L., Nick, A. M., McNeish, I. A., Balkwill, F., Han, H. D., Bottsford-Miller, J., Rupaimoole, R., Armaiz-Pena, G. N., Pecot, C. V., Coward, J., Deavers, M. T., Vasquez, H. G., Urbauer, D., Landen, C. N., Hu, W., Gershenson, H., Matsuo, K., Shahzad, M. M. K., King, E. R., Tekedereli, I., Ozpolat, B., Ahn, E. H., Bond, V. K., Wang, R., Drew, A. F., Gushiken, F., Lamkin, D., Collins, K., DeGeest, K., Lutgendorf, S. K., Chiu, W., Lopez-Berestein, G., Afshar-Kharghan, V., \& Sood, A. K. (2012). Paraneoplastic thrombocytosis in ovarian cancer. The New England Journal of Medicine, 366(7), 610-618.

58. Gasic, G. J., Gasic, T. B., \& Stewart, C. C. (1968). Antimetastatic effects associated with platelet reduction. Proceedings of the National Academy of Sciences of the United States of America, 61(1), 46-52.

59. Nieswandt, B., Hafner, M., Echtenacher, B., \& Mannel, D. N. (1999). Lysis of tumor cells by natural killer cells in mice is impeded by platelets. Cancer Research, 59(6), 1295-1300.
60. Etulain, J., Fondevila, C., Negrotto, S., \& Schattner, M. (2013). Platelet-mediated angiogenesis is independent of VEGF and fully inhibited by aspirin. British Journal of Pharmacology, 170(2), 255-265.

61. Maity, G., De, A., Das, A., Banerjee, S., Sarkar, S., \& Banerjee, S. K. (2015). Aspirin blocks growth of breast tumor cells and tumorinitiating cells and induces reprogramming factors of mesenchymal to epithelial transition. Laboratory Investigation; a journal of technical methods and pathology, 95(7), 702-717.

62. Guillem-Llobat, P., Dovizio, M., Bruno, A., Ricciotti, E., Cufino, V., Sacco, A., Grande, R., Alberti, S., Arena, V., Cirillo, M., Patrono, C., FitzGerald, G. A., Steinhilber, D., Sgambato, A., \& Patrignani, P. (2016). Aspirin prevents colorectal cancer metastasis in mice by splitting the crosstalk between platelets and tumor cells. Oncotarget, 7(22), 32462-32477.

63. Yu, L. X., Yan, L., Yang, W., Wu, F. Q., Ling, Y., Chen, S. Z., Tang, L., Tan, Y. X., Cao, D., Wu, M. C., Yan, H. X., \& Wang, H. Y. (2014). Platelets promote tumour metastasis via interaction between TLR4 and tumour cell-released high-mobility group box 1 protein. Nature Communications, 5, 5256.

64. Chan, A. T., Ogino, S., \& Fuchs, C. S. (2009). Aspirin use and survival after diagnosis of colorectal cancer. JAMA, 302(6), 649658.

65. Chen, E. P., Markosyan, N., Connolly, E., Lawson, J. A., Li, X., Grant, G. R., Grant, G. R., Grosser, T., FitzGerald, G. A., \& Smyth, E. M. (2014). Myeloid cell COX-2 deletion reduces mammary tumor growth through enhanced cytotoxic T-lymphocyte function. Carcinogenesis, 35(8), 1788-1797.

66. Markosyan, N., Li, J., Sun, Y. H., Richman, L. P., Lin, J. H., Yan, F., Quinones, L., Sela, Y., Yamazoe, T., Gordon, N., Tobias, J. W., Byrne, K. T., Rech, A. J., FitzGerald, G. A., Stanger, B. Z., \& Vonderheide, R. H. (2019). Tumor cell-intrinsic EPHA2 suppresses anti-tumor immunity by regulating PTGS2 (COX-2). The Journal of Clinical Investigation, 129(9), 3594-3609.

67. Frere, C., Lejeune, M., Kubicek, P., Faille, D., Marjanovic, Z., \& Cancer, G. F. T. e. (2019). Antiplatelet agents for cancer prevention: current evidences and continuing controversies. Cancers (Basel), 11(11), 1639.

68. Tullemans, B. M. E., Nagy, M., Sabrkhany, S., Griffioen, A. W., Oude Egbrink, M. G. A., Aarts, M., et al. (2018). Tyrosine kinase inhibitor pazopanib inhibits platelet procoagulant activity in renal cell carcinoma Patients. Frontiers in Cardiovascular Medicine, 5, 142.

69. Sabrkhany, S., Griffioen, A. W., Pineda, S., Sanders, L., Mattheij, N., van Geffen, J. P., Aarts, M. J., Heemskerk, J. W. M., oude Egbrink, M. G. A., \& Kuijpers, M. J. E. (2016). Sunitinib uptake inhibits platelet function in cancer patients. European Journal of Cancer, 66, 47-54.

70. Walraven, M., Homs, M. Y. V., van der Veldt, A. A. M., Dekker, H., Koldenhof, J., Honeywell, R., Barendrecht, A., Sebastian, S. A. E., Parr, N., Koekman, A. C., Voest, E. E., Roest, M., Korporaal, S. J. A., \& Verheul, H. M. W. (2018). Platelet function is disturbed by the angiogenesis inhibitors sunitinib and sorafenib, but unaffected by bevacizumab. Angiogenesis, 21(2), 325-334.

71. Kerr, B. A., Miocinovic, R., Smith, A. K., Klein, E. A., \& Byzova, T. V. (2010). Comparison of tumor and microenvironment secretomes in plasma and in platelets during prostate cancer growth in a xenograft model. Neoplasia, 12(5), 388-396.

72. Kasuga, I., Makino, S., Kiyokawa, H., Katoh, H., Ebihara, Y., \& Ohyashiki, K. (2001). Tumor-related leukocytosis is linked with poor prognosis in patients with lung carcinoma. Cancer, 92(9), 2399-2405.

73. Pucci, F., Rickelt, S., Newton, A. P., Garris, C., Nunes, E., Evavold, C., Pfirschke, C., Engblom, C., Mino-Kenudson, M., Hynes, R. O., Weissleder, R., \& Pittet, M. J. (2016). PF4 promotes 
platelet production and lung cancer growth. Cell Reports, 17(7), 1764-1772.

74. Rachidi, S., Md, P., Kaur, M. M., Lautenschlaeger, T. M., Li, Z., $\&$ Md, P. (2019). Platelet count correlates with stage and predicts survival in melanoma. Platelets, 30(8), 1042-1046.

75. Levin, J., \& Conley, C. L. (1964). Thrombocytosis associated with malignant disease. Archives of Internal Medicine, 114, 497-500.

76. Bailey, S. E., Ukoumunne, O. C., Shephard, E. A., \& Hamilton, W. (2017). Clinical relevance of thrombocytosis in primary care: a prospective cohort study of cancer incidence using English electronic medical records and cancer registry data. The British Journal of General Practice, 67(659), e405-e413.

77. Thon, J. N., Macleod, H., Begonja, A. J., Zhu, J., Lee, K. C., Mogilner, A., Hartwig, J. H., \& Italiano Jr., J. E. (2012). Microtubule and cortical forces determine platelet size during vascular platelet production. Nature Communications, 3, 852.

78. Handtke, S., Steil, L., Greinacher, A., \& Thiele, T. (2018). Toward the relevance of platelet subpopulations for transfusion medicine. Frontiers in Medicine (Lausanne), 5, 17.

79. Chu, S. G., Becker, R. C., Berger, P. B., Bhatt, D. L., Eikelboom, J. W., Konkle, B., et al. (2010). Mean platelet volume as a predictor of cardiovascular risk: a systematic review and meta-analysis. Journal of Thrombosis and Haemostasis, 8(1), 148-156.

80. Berger, J. S., Eraso, L. H., Xie, D., Sha, D., \& Mohler 3rd, E. R. (2010). Mean platelet volume and prevalence of peripheral artery disease, the National Health and Nutrition Examination Survey, 1999-2004. Atherosclerosis, 213(2), 586-591.

81. Muscari, A., Puddu, G. M., Cenni, A., Silvestri, M. G., Giuzio, R., Rosati, M., Santoro, N., Bianchi, G., Magalotti, D., \& Zoli, M. (2009). Mean platelet volume (MPV) increase during acute nonlacunar ischemic strokes. Thrombosis Research, 123(4), 587-591.

82. Douda, T., Bures, J., Rejchrt, S., Kopacova, M., Pecka, M., \& Maly, J. (2006). Casopis Lékarů Ceských, 145(11), 870-873.

83. Jaremo, P., \& Sandberg-Gertzen, H. (1996). Platelet density and size in inflammatory bowel disease. Thrombosis and Haemostasis, 75(4), 560-561.

84. Pyo, J. S., Sohn, J. H., \& Kang, G. (2016). Diagnostic and prognostic roles of the mean platelet volume in malignant tumors: a systematic review and meta-analysis. Platelets, 27(8), 722-728.

85. Tuncel, T., Ozgun, A., Emirzeoglu, L., Celik, S., Bilgi, O., \& Karagoz, B. (2014). Mean platelet volume as a prognostic marker in metastatic colorectal cancer patients treated with bevacizumabcombined chemotherapy. Asian Pacific Journal of Cancer Prevention, 15(15), 6421-6423.

86. Kilincalp, S., Ekiz, F., Basar, O., Ayte, M. R., Coban, S., Yilmaz, B., et al. (2014). Mean platelet volume could be possible biomarker in early diagnosis and monitoring of gastric cancer. Platelets, 25(8), 592-594.

87. Kilincalp, S., Coban, S., Akinci, H., Hamamci, M., Karaahmet, F., Coskun, Y., et al. (2015). Neutrophil/lymphocyte ratio, platelet/ lymphocyte ratio, and mean platelet volume as potential biomarkers for early detection and monitoring of colorectal adenocarcinoma. European Journal of Cancer Prevention, 24(4), 328-333.

88. Wang, R., Stone, R. L., Kaelber, J. T., Rochat, R. H., Nick, A. M., Vijayan, K. V., Afshar-Kharghan, V., Schmid, M. F., Dong, J. F., Sood, A. K., \& Chiu, W. (2015). Electron cryotomography reveals ultrastructure alterations in platelets from patients with ovarian cancer. Proceedings of the National Academy of Sciences of the United States of America, 112(46), 14266-14271.

89. van der Meijden, P. E. J., \& Heemskerk, J. W. M. (2018). Platelet biology and functions: new concepts and clinical perspectives. Nature Reviews. Cardiology, 16, 166-179.

90. Baaten, C., Ten Cate, H., van der Meijden, P. E. J., \& Heemskerk, J. W. M. (2017). Platelet populations and priming in hematological diseases. Blood Reviews, 31(6), 389-399.
91. van der Loo, B., \& Martin, J. F. (1999). A role for changes in platelet production in the cause of acute coronary syndromes. Arteriosclerosis, Thrombosis, and Vascular Biology, 19(3), 672679.

92. Sansanayudh, N., Numthavaj, P., Muntham, D., Yamwong, S., McEvoy, M., Attia, J., Sritara, P., \& Thakkinstian, A. (2015). Prognostic effect of mean platelet volume in patients with coronary artery disease. A systematic review and meta-analysis. Thrombosis and Haemostasis, 114(6), 1299-1309.

93. Mangalpally, K. K., Siqueiros-Garcia, A., Vaduganathan, M., Dong, J. F., Kleiman, N. S., \& Guthikonda, S. (2010). Platelet activation patterns in platelet size sub-populations: differential responses to aspirin in vitro. Journal of Thrombosis and Thrombolysis, 30(3), 251-262.

94. Kunicki, T. J., Williams, S. A., Nugent, D. J., \& Yeager, M. (2012). Mean platelet volume and integrin alleles correlate with levels of integrins alpha(IIb)beta(3) and alpha(2)beta(1) in acute coronary syndrome patients and normal subjects. Arteriosclerosis, Thrombosis, and Vascular Biology, 32(1), 147-152.

95. Khaspekova, S. G., Zyuryaev, I. T., Yakushkin, V. V., Sirotkina, O. V., Zaytseva, N. O., Ruda, M. Y., Panteleev, M. A., \& Mazurov, A. V. (2014). Relationships of glycoproteins IIb-IIIa and $\mathrm{Ib}$ content with mean platelet volume and their genetic polymorphisms. Blood Coagulation \& Fibrinolysis, 25(2), 128-134.

96. Al-Mondhiry, H. (1983). beta-Thromboglobulin and plateletfactor 4 in patients with cancer: correlation with the stage of disease and the effect of chemotherapy. American Journal of Hematology, 14(2), 105-111.

97. Tsiara, S., Elisaf, M., Jagroop, I. A., \& Mikhailidis, D. P. (2003). Platelets as predictors of vascular risk: is there a practical index of platelet activity? Clinical and Applied Thrombosis/Hemostasis, 9(3), 177-190

98. Braekkan, S. K., Mathiesen, E. B., Njolstad, I., Wilsgaard, T., Stormer, J., \& Hansen, J. B. (2010). Mean platelet volume is a risk factor for venous thromboembolism: the Tromso Study, Tromso, Norway. Journal of Thrombosis and Haemostasis, 8(1), $157-162$.

99. Kostrubiec, M., Labyk, A., Pedowska-Wloszek, J., HrynkiewiczSzymanska, A., Pacho, S., Jankowski, K., Lichodziejewska, B., \& Pruszczyk, P. (2010). Mean platelet volume predicts early death in acute pulmonary embolism. Heart, 96(6), 460-465.

100. Shen, X. M., Xia, Y. Y., Lian, L., Zhou, C., Li, X. L., Han, S. G., Zheng, Y., Gong, F. R., Tao, M., Mao, Z. Q., \& Li, W. (2016). Mean platelet volume provides beneficial diagnostic and prognostic information for patients with resectable gastric cancer. Oncology Letters, 12(4), 2501-2506.

101. Yin, J. B., Wang, X., Zhang, X., Liu, L., \& Wang, R. T. (2018) Mean platelet volume predicts survival in pancreatic cancer patients with synchronous liver metastases. Scientific Reports, 8(1), 6014.

102. Lucijanic, M., Mitrovic, Z., Cicic, D., Prka, Z., Pejsa, V., Livun, A., Stoos-Veic, T., Romic, Z., Zivkovic, M., Lucijanic, I., Fabris, Z., \& Kusec, R. (2018). Increased mean platelet volume (MPV) is an independent predictor of inferior survival in patients with primary and secondary myelofibrosis. International Journal of Hematology, 107(2), 166-172.

103. Zhu, X., Cao, Y., Lu, P., Kang, Y., Lin, Z., Hao, T., \& Song, Y. (2018). Evaluation of platelet indices as diagnostic biomarkers for colorectal cancer. Scientific Reports, 8(1), 11814.

104. Kurtoglu, E., Kokcu, A., Celik, H., Sari, S., \& Tosun, M. (2015). Platelet indices may be useful in discrimination of benign and malign endometrial lesions, and early and advanced stage endometrial cancer. Asian Pacific Journal of Cancer Prevention, 16(13), 5397-5400.

105. Zaslavsky, A., Baek, K. H., Lynch, R. C., Short, S., Grillo, J., Folkman, J., Italiano Jr., J. E., \& Ryeom, S. (2010). Platelet- 
derived thrombospondin-1 is a critical negative regulator and potential biomarker of angiogenesis. Blood, 115(22), 4605-4613.

106. Cervi, D., Yip, T. T., Bhattacharya, N., Podust, V. N., Peterson, J., Abou-Slaybi, A., Naumov, G. N., Bender, E., Almog, N., Italiano Jr., J. E., Folkman, J., \& Klement, G. L. (2008). Platelet-associated PF-4 as a biomarker of early tumor growth. Blood, 111(3), 12011207.

107. Wiesner, T., Bugl, S., Mayer, F., Hartmann, J. T., \& Kopp, H. G. (2010). Differential changes in platelet VEGF, Tsp, CXCL12, and CXCL4 in patients with metastatic cancer. Clinical \& Experimental Metastasis, 27(3), 141-149.

108. Klement, G. L., Yip, T. T., Cassiola, F., Kikuchi, L., Cervi, D., Podust, V., et al. (2009). Platelets actively sequester angiogenesis regulators. Blood, 113(12), 2835-2842.

109. Italiano Jr., J. E., \& Battinelli, E. M. (2009). Selective sorting of alpha-granule proteins. Journal of Thrombosis and Haemostasis, 7(Suppl 1), 173-176.

110. Nilsson, R. J., Balaj, L., Hulleman, E., van Rijn, S., Pegtel, D. M., Walraven, M., et al. (2011). Blood platelets contain tumor-derived RNA biomarkers. Blood, 118(13), 3680-3683.

111. Fisher, M. H., \& Di Paola, J. (2018). Genomics and transcriptomics of megakaryocytes and platelets: implications for health and disease. Research and Practice in Thrombosis and Haemostasis, 2(4), 630-639.

112. Sol, N., \& Wurdinger, T. (2017). Platelet RNA signatures for the detection of cancer. Cancer Metastasis Reviews, 36(2), 263-272.

113. Vickers, K. C., Palmisano, B. T., Shoucri, B. M., Shamburek, R. D., \& Remaley, A. T. (2011). MicroRNAs are transported in plasma and delivered to recipient cells by high-density lipoproteins. Nature Cell Biology, 13(4), 423-433.

114. Arroyo, J. D., Chevillet, J. R., Kroh, E. M., Ruf, I. K., Pritchard, C. C., Gibson, D. F., Mitchell, P. S., Bennett, C. F., PogosovaAgadjanyan, E. L., Stirewalt, D. L., Tait, J. F., \& Tewari, M. (2011). Argonaute2 complexes carry a population of circulating microRNAs independent of vesicles in human plasma. Proceedings of the National Academy of Sciences of the United States of America, 108(12), 5003-5008.

115. Nassa, G., Giurato, G., Cimmino, G., Rizzo, F., Ravo, M., Salvati, A., Nyman, T. A., Zhu, Y., Vesterlund, M., Lehtiö, J., Golino, P., Weisz, A., \& Tarallo, R. (2018). Splicing of platelet resident premRNAs upon activation by physiological stimuli results in functionally relevant proteome modifications. Scientific Reports, 8(1), 498.

116. Biino, G., Santimone, I., Minelli, C., Sorice, R., Frongia, B., Traglia, M., Ulivi, S., di Castelnuovo, A., Gögele, M., Nutile, T., Francavilla, M., Sala, C., Pirastu, N., Cerletti, C., Iacoviello, L., Gasparini, P., Toniolo, D., Ciullo, M., Pramstaller, P., Pirastu, M., de Gaetano, G., \& Balduini, C. L. (2013). Age- and sexrelated variations in platelet count in Italy: a proposal of reference ranges based on 40987 subjects' data. PLoS ONE, 8(1), e54289.

117. Caine, G. J., Lip, G. Y., \& Blann, A. D. (2004). Platelet-derived VEGF, Flt-1, angiopoietin-1 and P-selectin in breast and prostate cancer: further evidence for a role of platelets in tumour angiogenesis. Annals of Medicine, 36(4), 273-277.
118. Alkozai, E. M., Porte, R. J., Adelmeijer, J., Zanetto, A., Simioni, P., Senzolo, M., \& Lisman, T. (2015). Levels of angiogenic proteins in plasma and platelets are not different between patients with hepatitis B/C-related cirrhosis and patients with cirrhosis and hepatocellular carcinoma. Platelets, 26(6), 577-582.

119. Strohkamp, S., Gemoll, T., Humborg, S., Hartwig, S., Lehr, S., Freitag-Wolf, S., Becker, S., Franzén, B., Pries, R., Wollenberg, B., Roblick, U. J., Bruch, H. P., Keck, T., Auer, G., \& Habermann, J. K. (2018). Protein levels of clusterin and glutathione synthetase in platelets allow for early detection of colorectal cancer. Cellular and Molecular Life Sciences, 75(2), 323-334.

120. Di Vito, C., Navone, S. E., Marfia, G., Abdel Hadi, L., Mancuso, M. E., Pecci, A., et al. (2017). Platelets from glioblastoma patients promote angiogenesis of tumor endothelial cells and exhibit increased VEGF content and release. Platelets, 28(6), 585-594.

121. Chater, C., Bauters, A., Beugnet, C., M'Ba, L., Rogosnitzky, M., \& Zerbib, P. (2018). Intraplatelet vascular endothelial growth factor and platelet-derived growth factor: new biomarkers in carcinoembryonic antigen-negative colorectal cancer? Gastrointestinal Tumors, 5(1-2), 32-37.

122. Han, H., Cao, F. L., Wang, B. Z., Mu, X. R., Li, G. Y., \& Wang, $X$. W. (2014). Expression of angiogenesis regulatory proteins and epithelial-mesenchymal transition factors in platelets of the breast cancer patients. Scientific World Journal, 2014, 878209.

123. Mayer, E. L., Isakoff, S. J., Klement, G., Downing, S. R., Chen, W. Y., Hannagan, K., Gelman, R., Winer, E. P., \& Burstein, H. J. (2012). Combination antiangiogenic therapy in advanced breast cancer: a phase 1 trial of vandetanib, a VEGFR inhibitor, and metronomic chemotherapy, with correlative platelet proteomics. Breast Cancer Research and Treatment, 136(1), 169-178.

124. Holmes, C. E., Levis, J. E., Schneider, D. J., Bambace, N. M., Sharma, D., Lal, I., Wood, M. E., \& Muss, H. B. (2016). Platelet phenotype changes associated with breast cancer and its treatment. Platelets, 27(7), 703-711.

125. Benoy, I., Salgado, R., Colpaert, C., Weytjens, R., Vermeulen, P. B., \& Dirix, L. Y. (2002). Serum interleukin 6, plasma VEGF, serum VEGF, and VEGF platelet load in breast cancer patients. Clinical Breast Cancer, 2(4), 311-315.

126. Fu, B. H., Fu, Z. Z., Meng, W., Gu, T., Sun, X. D., \& Zhang, Z. (2015). Platelet VEGF and serum TGF-betal levels predict chemotherapy response in non-small cell lung cancer patients. Tumour Biology, 36(8), 6477-6483.

127. Verheul, H. M., Hoekman, K., Luykx-de Bakker, S., Eekman, C. A., Folman, C. C., Broxterman, H. J., \& Pinedo, H. M. (1997). Platelet: transporter of vascular endothelial growth factor. Clinical Cancer Research, 3(12 Pt 1), 2187-2190.

Publisher's note Springer Nature remains neutral with regard to jurisdictional claims in published maps and institutional affiliations. 